\title{
Doing the possible: harm reduction, injecting drug use and blood borne viral infections in Australia
}

\author{
Wendy Loxley* \\ National Drug Research Institute \\ Preventing Harmful Drug Use in Australia
}

Curtin University Of Technology

Perth, Western Australia

\begin{abstract}
Paper presented at the Australasian Society for HIV Medicine $11^{\text {th }}$ Annual Conference, 9-11 December 1999, Perth
\end{abstract}

*Correspondence to:

Associate Professor Wendy Loxley

National Drug Research Institute

PO Box U1987

PERTH WA 6845

AUSTRALIA 


\section{Abstract}

Most surveys show that, other than among men who inject drugs and have a history of homosexual contact, the prevalence of HIV infection among injecting drug users (IDUs) in Australia is about 2\%. Rates of needle sharing have also declined greatly in the last decade, although the high prevalence and incidence of hepatitis $\mathrm{C}$ infection suggest that existing strategies have not yet brought this epidemic under control.

Harm reduction has been the major Australian approach to the reduction of blood borne viral infections (BBVIs) in IDUs. Harm reduction strategies include needle distribution schemes, drug substitution therapies and education about safe administration practices. Importantly, with IDUs as with gay men, the infected and affected communities have been brought into partnership with health educators, researchers and policy makers. This paper will review Australia's approach to the prevention of BBVI in IDUs and the effectiveness of current strategies. I will argue that while HIV/AIDS among heterosexual IDUs appears to have been successfully prevented, international experiences of rapidly emerging epidemics demonstrate there is little room for complacency. Moreover, reducing the incidence of hepatitis $\mathrm{C}$ and hepatitis $\mathrm{B}$ among IDUs remains a major challenge.

Keywords: Harm reduction, Blood borne viruses, Injecting drug users, Policy, Australia 
Doing harm reduction is contentious. There are debates about which harms to which people should be reduced, and how these can be measured, and whether abstinence based policies reduce harm more effectively than those which focus on safer behaviour (Hawks \& Lenton, 1998). In Australia, however, there has been some consensus about approaches to reducing HIV/AIDS in injecting drug users. Harm reduction strategies, which were understood to be those which decreased the prevalence of behaviours which caused the virus to be transmitted although they might not reduce injecting or other drug use, have been part of national HIV/AIDS policy from the outset. Australia has limited the spread of HIV/AIDS in IDUs by adopting harm reduction policies. It is a different story with the other BBVIs, hepatitis C and hepatitis B.

In this paper I will briefly overview the Australian epidemics of HIV and hepatitis C as they affect IDUs. I will then discuss the role of some of the major harm reduction strategies - needle and syringe provision, drug treatment and education and prevention programs - in reducing the harms associated with these epidemics. I will outline what I consider to be some of the major threats to the current position - the reduction in support for some programs, the situations in prisons and some cautionary tales from other countries. I will conclude by briefly considering the ‘forgotten’ epidemic - hepatitis B.

\section{The epidemics}

The success of harm reduction strategies in preventing an epidemic of HIV/AIDS among heterosexual IDUs in Australia has been evident for some years. The 1999 annual surveillance report on BBVIs in Australia, for example, reports that approximately 8\% of HIV diagnoses in Australia have been among people who inject drugs, but that about half 
of these are among men who also report a history of homosexual contact. The same report notes that HIV prevalence was less than $0.6 \%$ among female and male IDUs seen at sexual health centres between 1993 and 1998, and less than 3\% among heterosexuals attending needle and syringe programs (NSPs) (NCHECR, 1999). This rate has remained largely unchanged since the first NSP survey in 1995. That this is an exceptional figure can be seen by comparison of rates of infection in comparable countries in Europe, in the United States and our neighbours in South East Asia.

Hepatitis C is, of course, a very different epidemic with an estimated 200000 infections, compared to an estimated total of $17600 \mathrm{HIV}$ infections. More than 125000 people have been notified with hepatitis C since antibody testing became available in 1990, and there are now around 18000 - 20000 notifications a year (NCHECR, 1999). Eighty percent of infections are considered to be as a result of injecting drugs (Lowe \& Cotton, 1999).

While there have been HIV/AIDS National Strategies since 1989, the hepatitis C virus was not identified until 1989, and the blood supply not secured until 1990 when a screening test became available. A National Hepatitis C Action Plan was developed in 1994 and a Nationally Coordinated Approach to Education and Prevention was put in place in 1995. Hepatitis C was included as a 'Related Disease' in the 1996-97 Third National HIV/AIDS Strategy. The National Hepatitis C Action Plan has recently been reviewed and a detailed report made. One of the responses to this report has been a decision that there will be a National Hepatitis C Strategy, linked to, but separate from, the next HIV/AIDS Strategy. 
The determinants of both HIV/AIDS and hepatitis C epidemics are background virus prevalence, viral infectiousness and the existence of behaviour that permits spread but hepatitis $\mathrm{C}$ is more infectious than HIV which means that smaller amounts of blood can transmit the infection (Crofts, Aitken \& Kaldor,1999). While enough IDUs have stopped sharing needles to limit the spread of HIV, environmental contamination with infected blood during an injecting occasion may be enough to transmit hepatitis $\mathrm{C}$, and these are contaminations of which the average IDU may be largely unaware (Carruthers, 1999). And finally, as Crofts et al. (1999) succinctly state,

“The difference in incidence comes down to the force of numbers ... An IDU sharing a needle used by another IDU of unknown infection status is at somewhere between 150 and 800 times higher risk of infection with HCV than HIV” (p. 220) The review of the National Hepatitis C Action Plan noted that an infrastructure of NSPs, methadone programs, and education programs for IDUs existed by the time HCV was identified, and that community based organisations - drug users’ groups and more recently hepatitis C councils - have been funded in most jurisdictions. Despite these programs, however, enough blood to blood contact between IDUs is occurring for the epidemic to be maintained. This seems to suggest that education and prevention programs has not been sufficiently effective. The review also, however, noted that hepatitis $\mathrm{C}$ had not been accorded sufficient priority for a number of reasons including that it is a disease poorly understood by the general community (Lowe \& Cotton, 1999). 


\section{Needle and syringe programs}

Australia is justifiably famous around the world for its HIV/AIDS prevention programs. The corner stone of our endeavours to reduce BBVIs among IDUs has been programs which distribute sterile injecting equipment to drug injectors. The first pilot (and illegal) NSP in Australia was established in November 1986, with government funded NSPs set up from early 1987, first in NSW where there was perceived to be most need, but rapidly thereafter in other states (Wodak 1995). The first Western Australian NSP, for example, was set up in July 1987 (Loxley et al, 1991). NSPs are not the only source of sterile injecting equipment, however, and pharmacy sale of needles and syringes is an additional important aspect of the needle distribution program. Very few if any programs now insist on one to one exchange (Burrows, 1998) but exchange can be facilitated by providing free equipment in exchange for used equipment, and charging at a cost-recovery rate for non-exchanged equipment.

There is ample evidence, both Australian and international, that NSPs are effective in preventing HIV infection without being associated with a rise in drug use (Hurley, Jolley \& Kaldor, 1997; Lurie, 1997). In his evaluation of the National HIV/AIDS Strategy 1993/94 to 1995/96, Feachem (1995) estimated that 3000 cases of HIV were avoided in Australia in 1991 through the operation of NSPs, and that the savings in treatment costs due to the prevention of HIV infection more than offset the operating costs of the program. The most plausible assumptions suggested that this involved a saving of some \$267 million in 1991. 
The hepatitis $\mathrm{C}$ epidemic, however, far from being prevented, is being maintained by blood to blood contact, primarily through shared injecting equipment, and a central requirement for reducing it is to expand NSPs to meet distribution targets based on IDUs always using sterile injecting equipment. The current uncertain support of NSP programs by State and Territory governments, however, is a concern. ANCARD ${ }^{1}$, in their review of the Third National HIV/AIDS Strategy, pointed out that there had been steep rises in the number of people injecting drugs, but no uncapped funding to meet the exponentially increasing demand for injecting equipment:

"It will be difficult, if not impossible, for the States and Territories to continue to fund needle and syringe programs to the level required without compromising other programs” (ANCARD, 1999 p. 53).

This difficulty can be demonstrated in Western Australia. There has been a recent controversy over perceived shortfalls in State funding for needle exchange, which has only been resolved in the short term. While 2/3 of all WA injecting equipment is sold through pharmacies rather than given away, not all WA injectors can access sterile equipment for every injection. In a local study, injectors who purchased injecting equipment in pharmacies were asked to complete short questionnaires attached to the FitPacks ${ }^{2}$ that they bought. Over a third said that they had shared a needle because they did not have enough money to buy a FitPack, and 40\% reused their own equipment, often to save money (Lenton et al., in press).

\footnotetext{
${ }^{1}$ Australian National Council on AIDS and Related Diseases
} 
WA is not alone in finding difficulty in funding NSPs, and lack of political support for increased funding despite rises in injecting related to the increased availability of heroin appears to have been developing in Australia. There also appears be a political reality about epidemics the community is and is not prepared to tolerate. This point will be addressed below.

Injecting equipment provision is not the only element in the Australian approach to the reduction of BBVIs in IDUs. The expansion of drug treatment places, particularly in methadone maintenance treatment (MMT) has been another vitally important aspect of the approach.

It is clear that MMT assists in the reduction of HIV-risk behaviour and can reduce the incidence of HIV infection. Participation in MMT is related to less frequent injecting, less frequent sharing, fewer sharing partners and lower HIV seroprevalence (Darke,1992). It remains to be seen whether alternative pharmacotherapies for opiate dependence (LAAM, buprenorphine, naltrexone, tincture of opium and slow-release oral morphine, all of which are currently being trialled) will do as well. It appears that Australians are not going to know, at least for some years, whether the provision of heroin as a treatment modality would do as well as or better than methadone, despite encouraging signs from the Swiss heroin trials.

The question of whether MMT also reduces the risk of hepatitis C has not been resolved: one difficulty is that the rate of hepatitis $\mathrm{C}$ infection among methadone clients is usually

\footnotetext{
2 Pack of needles and syringes in rigid disposable container. At the time of the study all injecting equipment was sold to drug users in this form.
} 
so high (Selvey et al, 1997) that demonstrating prevention can be difficult. It should, however, be effective among those who are not already infected. To state the obvious, if MMT reduces the prevalence of injecting, the occasions on which there is a risk of HCV transmission are reduced. Since hepatitis C prevalence is closely linked to duration of injecting (Loxley et al., 1995) methadone and other treatments would be more effective against hepatitis C if they were undertaken earlier in the injector's career. The Federal Government's recent Tough on Drugs Diversion Program which will divert first time or minor drug offenders to compulsory assessment and referral to treatment or education is an early intervention approach along these lines and it will be important to monitor it carefully to see whether it is having a hepatitis C prevention effect.

\section{Education and prevention programs}

The development of appropriately targeted education and prevention programs is another important aspect of HIV/AIDS strategies. Education of drug users about safe administration has undoubtedly been effective: rates of needle sharing have fallen since HIV/AIDS first became a concern, and in the four annual national NSP surveys, the rates of those who admitted using a needle after someone else in the previous month were $31 \%$ in 1995, 28\% in 1996, 14\% in 1997 and 18\% in 1998. Feachem (1995) commented that it was highly probable that not only NSPs, but also peer education and community development were responsible for the low prevalence of HIV/AIDS among IDUs in Australia.

Once again, however, we should be careful not to be complacent. Partnerships between the IDU community and health educators, researchers and policy makers are supposedly 
as important in the fight against HIV infection within the IDU community as within the gay community, and funding drug user organisations has been part of the approach. It has been pointed out, however, that while many funded drug users organisations could have played a crucial role in peer education, resource production, research facilitation and policy advice, most were only funded to provide peer-based needle exchange. This hardly allowed for the optimisation of their role although with adequate support, training and funding, drug users’ groups could play a significant role as the consumer health and rights organisations for the IDU community (Moore,1995).

The hepatitis $\mathrm{C}$ epidemic has heightened and focused these concerns. The review of the National Action Plan received many submissions outlining concerns about the way that the partnership approach was played out in real life, and recommended a thorough review and refinement of existing strategies for participation of representatives of affected communities in policy and decision making at Commonwealth, State and Territory levels (Lowe \& Cotton, 1999). A number of other recommendations about building the capacity of community organisations to represent affected communities were also made, including the need to extend the focus. It has been argued that these partnership must include

“... current and past drug users, those who are just beginning to inject, and those who have left it far behind. ... we have organisations such as the hepatitis C councils, and the AIDS epidemic has left us with ... injecting drug user groups ... which provide us with links into the injecting community ... but the partnership must extend beyond this and into the wider community where past injecting drug users reside” (Orr \& Leeder, 1998, p. 193). 


\section{Prisons}

One of the threats to the stability of the low prevalence of HIV/AIDS among IDUs in Australia is the situation in our prisons. Injecting drug use is the main risk factor for HIV infection among prisoners (Seamark et al., 1997) but there is little harm reduction beyond some education in most Australian prisons. There is, however, plenty of evidence of risk behaviour. Dolan et al. (1998) reported that around 30\% of prisoners inject drugs, 20\% tattoo themselves and up to $10 \%$ engage in unprotected anal sex. Two studies found that HIV positive inmates were significantly more likely to inject and engage in sex than inmates who were uninfected or unsure. Needle sharing is common and, because needles are very difficult to come by, is different to sharing in the community which is primarily between close friends and lovers. In prisons, numerous strangers may share one needle (Dolan et al., 1998).

Dolan and Wodak (1996) have suggested that the extent of the transmission of HIV and other BBVIs occurring in prisons has been underestimated. They developed a mathematical model of HIV incidence in NSW prisons in 1993 and estimated that between 38 and 152 inmates were infected each year (Dolan et al, 1998).

These findings suggest that prisons should look carefully to policies which might reduce the rate of injecting risk behaviour. Prison methadone maintenance treatment (PMMT) is clearly one such. An international review of PMMT found that although there was no direct evidence that PMMT would reduce HIV transmission, there was evidence that it reduced injecting and sharing, and therefore likely to reduce transmission (Dolan \& Wodak, 1996). 
There are now some limited programs in NSW, Queensland, South Australia and Victoria some of which are under evaluation (Dolan, 1999) but there is considerable scope for expansion. Current approaches to the diversion of drug users away from custodial sentences also clearly have the potential to reduce the transmission of blood borne viruses in prisons, and evaluations should investigate that aspect of these programs.

In terns of hepatitis $\mathrm{C}$ in prisons, one estimate has been that $80 \%$ of NSW prisoners have chronic hepatitis C. Cases of contracting the disease within prison have been proven. Being in prison is a risk factor arising not only from intravenous drug use but from activity like tattooing using non-sterile equipment, sexual assaults which often involves drawing blood, other violence and self harm (Haber, 1999).

\section{Rapidly emerging epidemics}

Another concern is that of rapidly emerging HIV/AIDS epidemics. There are two Canadian epidemics which have been used as examples of what could happen in a country like Australia which has good NSP coverage and low HIV/AIDS seroprevalence; there is sufficient similarity between these epidemics and the situation in Sydney to suggest that Australians should not become complacent about low prevalence of HIV/AIDS among IDUs (Wodak, 1999).

The first example is Vancouver which introduced a needle exchange program (NEP) in 1988. Vancouver's NEP is the largest in North America, in 1997 exchanging over 2 million needles per year, and was, until recently, considered to be a major factor accounting for Vancouver's low HIV prevalence rate, which at the time of the introduction of the program, was estimated to be $1-2 \%$ among IDUs. In 1993 the NEP 
was evaluated by the US Centres for Disease Control and Prevention and ranked in the top three in North America in terms of number of syringes exchanged and returned, estimated proportion of IDUs reached, and number of client referrals to drug treatment and support services (Strathdee et al, 1997).

Since September 1994 there has, however, been a rapid increase in HIV infection with the proportion of IDUs testing HIV seropositive rising from 2 to $7 \%$ in an 18 month period. A new cohort study which recruited over 1000 IDUs, most of whom had attended the NEP, was initiated in 1996 to study this increase, and baseline HIV prevalence was found to be $23.2 \%$. After 8 months of follow-up the preliminary estimate of HIV incidence was between 16.5 and 18.6 per 100 person-years. It was concluded that these results "were consistent with an on-going and serious outbreak of HIV infection among IDU in Vancouver” (Strathdee et al, 1997, p. F63). The researchers also believed that needle sharing in this population was normal, and that little if any behaviour change resulted from a HIV-positive test result.

These findings have been interpreted by some as evidence that NEPs do not work although this is contrary to the bulk of the literature:

“In cities were NEP is part of a comprehensive program that includes HIV testing, counselling, education and drug treatment options, HIV incidence and associated risk behaviours have declined significantly over time” (Strathdee et al, 1997, p. F63).

In Vancouver, however, access to drug and alcohol treatment, methadone maintenance and counselling services remained inadequate (Strathdee et al, 1997). The researchers 
considered than a shift from heroin to cocaine use, with its associated increased frequency of injecting, might have been an important factor in Vancouver's escalating HIV prevalence and incidence, since cocaine injecting was more frequent among HIV positive IDUs, and appropriate treatment for cocaine use was more limited than opiate treatment. They concluded that NEP is a necessary but not sufficient element of HIV prevention among IDUs: other complementary strategies are also needed including treatment, education, and social services.

The other Canadian example centres upon Montreal. Bruneau et al. (1997) found that IDUs who attended the Montreal NEP were 2.2 times as likely to be HIV positive at baseline than non-attenders, and 1.7 times as likely to seroconvert during 15 months follow-up. Although these findings, like those in the Vancouver experience, have been used to argue that needle exchange does not work, it is more likely that unusual local conditions in Montreal had attracted particularly high-risk IDUs to the NEP, bringing with them higher seroconversion rates (Lurie, 1997). The major conclusion from the Montreal study was that what was needed "to reduce the terrible toll” of HIV among Montreal IDUs was not less needle exchange but more (Bruneau et al, 1997).

As I noted earlier, the examples of Vancouver and Montreal have been used as a cautionary tale in Australia particularly as the shift to cocaine injecting identified in Vancouver, is becoming apparent in Sydney (MacDonald, McKetin et al, 1999). Other threats to the stability of HIV prevalence among IDUs are associations between social disadvantage and HIV seropositivity: in Vancouver, for example, what was termed 'unstable housing' and low education were the only two independent predictors of HIVpositive serostatus. In Sydney, cocaine injecting has been observed among sex workers 
and other socially disadvantaged groups. It remains to be seen whether cocaine injecting will spread to other parts of the city bringing with it an increased risk of BBVIs in IDUs.

\section{Hepatitis B: the 'forgotton' epidemic}

Hepatitis B was identified long before HIV/AIDS and hepatitis C but, perhaps because of this, has never really assumed the same importance in the mind of injectors, the community and, possibly, health professionals. This is not a trivial disorder although comprehensive data on incidence, prevalence, morbidity and mortality in Australia is incomplete (Kaldor et al, 1996).

It is almost 20 years since the National Health and Medical Research Council called for all IDUs to be vaccinated against hepatitis B because of their high risk status (Gust, 1992), but it is clear that this has not occurred. As an example, in a recent study about blood borne virus testing and vaccination among IDUs, undertaken by myself and colleagues, 70\% of 200 IDUs had been tested for hepatitis B but only $24 \%$ had been vaccinated although many of the non-vaccinated had been found to be seronegative. Many of those who had not been vaccinated, moreover, reported that had never heard of vaccination or been offered it. Some did not understand why IDUs were at risk of hepatitis B, or why they should be vaccinated. Some were concerned about the cost of vaccination when the experience of those who had been vaccinated demonstrated that free vaccine was available (Loxley et al., 2000).

It seems extraordinary that when so many of the respondents in this study had been tested because they were IDUs, so few had been vaccinated, particularly when many of these 
had received a negative hepatitis B test. Clearly, opportunities for prevention of this disease had been squandered.

\section{Conclusion}

If HIV/AIDS had exploded among Australian IDUs as it did in other countries, it could have leapt into the general community with disastrous results. That it did not was partly because of far sighted and non-partisan action on the part of politicians, and their preparedness to put into place harm reduction strategies which, it could be supposed, the community would have difficulty, at least at first, in understanding or supporting.

Hepatitis C is different. Not as terrible as HIV/AIDS, but far more prevalent. Many will not die of it, but the lives they will live with it will be diminished and difficult. They will not be as productive as healthy people. There will be many with severe liver disease and our public health systems may find themselves having to make decisions about who should and who should not be eligible for liver transplants.

As I noted at the outset, as long as the major concern was HIV/AIDS there was less contention about harm reduction in the area of injecting drug use and blood borne viruses than in some other areas. Arguably, the non-drug using community could be convinced that almost any strategy, not matter what it did, or how much it cost, was the right strategy if it reduced the risk to them. But is that still true? Support for harm reduction appears to be waning, and the rhetoric of 'mutual obligation' is taking over. It is hard to avoid the conclusion that our political decision-makers do not care about hepatitis $\mathrm{C}$ in the same way as they did about HIV/AIDS, because the general community is not at the same risk. 
In these circumstances, it is perhaps not surprising that budgets for needles and syringes have been capped and show no signs of expanding. It may not be surprising that hepatitis C flourishes in prisons but to date the response has been little more than tokenistic. It may not be surprising that Australians have a universal hepatitis B vaccination policy for infants and pre-adolescents, but IDUs are not told that a vaccine is available.

Perhaps one of the most encouraging recent moves has been the recognition of the need for a National Hepatitis C Strategy, which is now being drafted. Not only because hepatitis $\mathrm{C}$ is a different disease which needs different strategies, but because it is important to name it. As long as hepatitis C was lost under the rubric of 'related diseases' it was easy to conceive of it as secondary to the main disease - HIV/AIDS.

For Australian IDUs the main disease is hepatitis C. The community should put as much effort into reducing the harm of hepatitis C, as it did into preventing IDUs - and themselves - from becoming infected with HIV/AIDS. 


\section{References}

This article was published in International Journal of Drug Policy,11 (6),W.Loxley, Doing the possible: harm reduction, injecting drug use and blood borne viral infections in Australia pp. 407-416, Copyright (2000), and is posted with permission from Elsevier.

ANCARD (1999) Proving Partnerships. Review on the National HIV/AIDS Strategy 1996-97 to 1998-99. Canberra: Commonwealth of Australia.

Bruneau, J., Lamothe, F., Franco F. et al. (1997) High rates of HIV infection among injection drug users participating in needle exchange programs in Montreal: results of a cohort study. American Journal of Epidemiology, 146, 994-1002.

Burrows, D. (1998) Injecting equipment in Australia: the state of play, Substance Use and Misuse, 33 (5) 1113-1127.

Carruthers, S. (1999) Beyond sharing: hepatitis C risks associated with injecting. Paper presented at Second Australasian Conference on Hepatitis C. Christchurch, New Zealand 16 - 18th August.

Crofts, N., Aitken, C. \& Kaldor, J. (1999) The force of numbers: why hepatitis C us spreading among Australian injecting drug users while HIV is not. Medical Journal of Australia, 170, 220-221.

Darke, S. (1992) Injecting drug users and the Human Immunodeficiency Virus: what do we know? Drug and Alcohol Review, 11 (2) 153-162.

Dolan, K. \& Wodak, A. (1996) An international review of methadone provision in prisons. Addiction Research, 4, 1, 85-96. 
Dolan, K., Wodak, A., Hall, W. \& Kaplan, E. (1998) A mathematical model of HIV transmission in NSW prisons. Drug and Alcohol Dependence, 50 (2) 197-202.

Dolan, K. (1999) National action plan for the surveillance and prevention of hepatitis $C$ infection in Australian prisons. Sydney: University of New South Wales, National Drug and Alcohol Research Centre and National Centre in HIV Epidemiology and Clinical Research.

Feachem, R.G.A. (1995) Valuing the past... Investing in the future. Evaluation of the National HIV/AIDS Strategy 1993-94 to 1994-96. AIDS/Communicable Diseases Branch, Commonwealth Department Of Human Services And Health. Canberra: AGPS.

Gust, I.D. (1992) Control of hepatitis B in Australia. The case for alternative strategies. Medical Journal of Australia, 156, 15, 819-820.

Haber, P. (1999) Hepatitis C in prisoners: incidence, prevalence and management. Paper presented at The 1999 Annual APSAD Conference, 8 - 10 November, Canberra.

Hawks, D. \& Lenton, S. (1998) Harm minimization: a basis for decision making in drug policy? Risk, Decision and Policy, 3 (2) 157-163.

Hurley, S.F., Jolley, D.J. \& Kaldor, J.N. (1997) Effectiveness of needle exchange programs for prevention for HIV infection. Lancet, 349, 1797-1800.

Kaldor, J.M., Plant, A.J., Thompson, S.C., Longbottom, H. \& Rowbottom, J. (1996) The incidence of hepatitis B infection in Australia: an epidemiological review. Medical Journal of Australia, 165, 322-326. 
Lenton, S., Kerry, K., Loxley, W., Tan-Quigley, A. \& Greig, R. (in press) Citizens who inject drugs: the 'Fitpack' study. International Journal of Drug Policy.

Lowe, D. \& Cotton, R. (1999) Hepatitis C: a review of Australia’s response. Department of Health and Aged Care, Canberra: AGPS.

Loxley, W., Carruthers, S. \& Bevan, J. (1995) In the same vein. First report of the Australian Study of HIV and Injecting Drug Use (ASHIDU). Perth: National Centre for Research into the Prevention of Drug Abuse, Curtin University of Technology.

Loxley, W., Davidson, P., Heale, P. \& Sullivan, P. (2000) Drawing blood: injecting drug users, blood borne viruses, testing and vaccination. Perth: National Centre for Research into the Prevention of Drug Abuse, Curtin University of Technology.

Loxley, W., Marsh, A., Watt, P., Westlund, G., Watson, C. \& Kosky, M. (1991) Western Australian initiatives to prevent the spread of HIV/AIDS among injecting drug users. The International Journal on Drug Policy, 2 (4), 13-16

Lurie, P. (1997) Invited Commentary: Le Mystere de Montreal. American Journal of Epidemiology, 146 (12) 1003-1005.

MacDonald, M. \& McKetin, R. on behalf on the Collaboration of Australian Needle and Syringe Program (1999) Drug use trends among injecting drug users, Drug Trends Bulletin, IDRS Illicit Drug Reporting System, October.

Moore, T. (1995) Education and prevention for IDUs on the decline. National AIDS Bulletin, 9 (2) 6-7 
National Centre in HIV Epidemiology and Clinical Research (Eds) (1999) HIV/AIDS, Hepatitis C \& Sexually Transmissible Infections in Australia, Annual Surveillance Report. Darlinghurst.

Orr, N. \& Leeder, S. (1998) The public health challenge of hepatitis C. Australian and New Zealand Journal of Public Health, 22 (2) 191-195.

Seamark, R.W., Gaughwin, M., Owen, N. \& Liew, C. (1997) HIV infection in South Australian prisons 1989-1994. Australian and New Zealand Journal of Public Health, 21, 6, 572-576.

Selvey, L.A., Denton, M. \& Plant, A.J. (1997) The incidence and prevalence of hepatitis C among clients of a Brisbane methadone clinic; factors influencing hepatitis C serostatus. Australian and New Zealand Journal of Public Health, 21 (1) 102-104.

Strathdee, S.A., Patrick, D.M. \& Currie, S.L. (1997) Needle exchange is not enough; lessons from the Vancouver injecting drug use study. AIDS, 11, 8, F59-F65.

Wodak, A. (1995). Needle exchange and bleach distribution programmes: the Australian experience. The International Journal on Drug Policy, 6 (1) 46-57.

Wodak, A. (1999) Sydney: Will we snatch defeat from the jaws of victory? Paper presented at $10^{\text {th }}$ International Conference on the Reduction of Drug Related Harm, 21-25 March, Geneva. 